\title{
Measuring provisions for collateralised retail lending
}

\author{
C.H. Hui ${ }^{\mathrm{a}, *}$, C.F. Lo ${ }^{\mathrm{b}}$, T.C. Wong ${ }^{\mathrm{a}}$, P.K. Man ${ }^{\mathrm{b}}$ \\ ${ }^{a}$ Research Department, Hong Kong Monetary Authority, 55th Floor, Two International Financial Centre, \\ 8 Finance Street, Central, Hong Kong, China \\ ${ }^{\mathrm{b}}$ Institute of Theoretical Physics and Department of Physics, The Chinese University of Hong Kong, \\ Shatin, Hong Kong, China
}

Received 23 November 2004; received in revised form 30 August 2005; accepted 10 April 2006

\begin{abstract}
This paper develops a simple model based on an options approach to measure provisions covering expected losses of collateralised retail lending due to default. The measurement of provisions against expected losses of retail lending secured by collateral is important for improving the capital adequacy framework for banks. The numerical results based on the model show that the loan-to-value ratio, correlation between the collateral value and the probability of default of borrowers in the pool, volatility of the collateral value, mean-reverting process of the probability of default and time horizon are the important factors for measuring provisions. (C) 2006 Elsevier Inc. All rights reserved.
\end{abstract}

JEL classification: $\mathrm{C} 60 ; \mathrm{G} 13 ; \mathrm{G} 28$

Keywords: Credit risk; Basel II; Provisioning

\section{Introduction}

While banks have faced difficulties over the years for a multitude of reasons, the major cause of serious banking problems continues to be directly related to lax credit standards for borrowers, poor portfolio risk management, or a lack of attention to changes in economic or other circumstances that can lead to a deterioration in the credit standing of a bank's counterparties. In view of this experience, the Basel Committee on Banking Supervision (2000) sets out the sound practices which specifically address establishing an appropriate credit risk environment and maintaining an

\footnotetext{
* Corresponding author. Tel.: +852 2878 1485; fax: +852 28782485.

E-mail addresses: Cho-Hoi_Hui@hkma.gov.hk (C.H. Hui), cflo@ phy.cuhk.edu.hk (C.F. Lo), eric_tc_wong@yahoo.com.hk (T.C. Wong).
} 
appropriate credit administration, measurement and monitoring process. These practices should also be applied in conjunction with a system in place for determining the adequacy of provisions.

In some countries, bank supervisors require banks' provisioning systems to be forward looking such that future changes in economic conditions that could have unfavourable effects on the banks' credit exposures should be taken into account. ${ }^{1}$ The level of provisions will be based on the banks' forecasts of collateral value and other macroeconomic conditions, regardless of the current losses, defaults and restructurings in their loans. On the other hand, in other countries, banks are required to determine provisions with reference to the losses, defaults and restructurings that have already occurred in their loans, according to detailed regulations on loan classification with minimum provisioning requirements. ${ }^{2}$ The rationale behind issuing detailed regulatory parameters could be to level the playing field or make bank regulations more easily enforceable. Under this approach, collateral is taken into account when classifying a loan, for example, to a more favourable category than that reflecting its own risk and determining the level of provisions accordingly.

While a central feature of provisioning systems is typically to refer to losses that have already been incurred or are anticipated with a high degree of confidence, provisioning requirements may differ significantly for several reasons. One is whether provisioning requirements aim at addressing only losses that follow from visible and identifiable events, or at establishing provisions for expected losses. Another issue is how banks are expected to factor in the value of collateral. In many countries, the value of collateral is then subtracted from the required provisions to determine the level of the actual provisions to be established.

Specific provisioning requirements are often designed for certain portfolio segments, such as retail loans including residential mortgage loans and credit card lending. Several countries (for example, Australia, France, Korea, The Netherlands, Saudi Arabia and Singapore) do not require retail loans to be classified and provisioned on an individual basis but allow them to be assessed on a pooled basis. In Australia, for example, management is allowed to deal with small consumer loans on a portfolio basis.

The Basel Committee is responsible for proposing regulatory requirements, including capital and provisioning requirements, for internationally active banks. Typically, bank supervisors around the world adopt the guidelines put forth by the Basel Committee. The Basel Committee first proposed the Basel New Capital Framework, also known as Basel II, in June 1999, with revisions in January 2001 and June 2004 (Basel, 2004). By year-end 2006, Basel II is expected to replace the current Basel Accord. Both the current and new capital adequacy frameworks are based on the concept of a capital ratio where the numerator represents the amount of capital of the bank available and the denominator is a measure of the risks faced by the bank and is referred to as risk-weighted assets. The resulting capital ratio must be no less than $8 \%$.

According to the proposals in Basel II, banks will be allowed to calculate regulatory capital charges for their credit exposures, including those in their retail portfolios, using the standardised approach or the internal ratings-based (IRB) approach. The standardised approach allows less sophisticated banks to use external credit ratings to classify their corporate, bank and sovereign assets into risk classes and to apply different defined risk weights to other assets including retail exposures. Over time, banks are expected to evolve to the IRB approach, which rely on the bank's own experience in determining the risk components of various asset classes.

\footnotetext{
1 The European Union provides principle-based rules, with only general guidance on how to determine adequate provisioning.

${ }^{2}$ Most emerging markets adopt this approach (see World Bank, 2002).
} 
The IRB calculation of risk-weighted assets for credit exposures relies on four basic risk components: (i) probability of default (PD), which measures the likelihood that the borrower will default over a given time horizon; (ii) loss-given-default (LGD), which measures the proportion of the exposure (after taking the presence and type of collateral into account) that will be lost if a default occurs; (iii) exposure-at-default, which measures the bank's exposure at the time of default; (iv) effective maturity. Different risk-weight functions based on the risk components are used by the IRB bank for calculating the corresponding risk-weighted assets of different types of credit exposures. There are three distinct IRB risk-weight functions for different classes of retail exposures: (i) residential mortgages; (ii) revolving credit; (iii) other retail loans.

Under the framework of Basel II, the IRB banks will also be required to compare their actual provisions with expected losses (see Basel, 2004). Any shortfall (i.e. the expected loss amount exceeds the provision amount) should be deducted from Tier 1 and Tier 2 capital of the bank and any excess (i.e. the provision amount exceeds the expected loss amount) will be eligible for inclusion in Tier 2 capital subject to a cap set by individual bank supervisors. It is therefore important to ensure adequate provisions being provided by banks against expected losses. Basel II defines expected loss as PD times LGD times exposure-at-default (see Basel, 2004). This makes the assumption that the PD and LGD are independent variables, i.e. uncorrelated. The time horizon of the PD and LGD estimates is defined to be 1 year. It is however noted that defaults are likely to be clustered during times of economic distress and LGD may be correlated with default rates. For example, an increase in defaults in residential mortgage loans leads to an increase in the supply of properties associated with those defaulted loans, and correspondingly to a reduction in their prices and to larger losses for banks.

The effects of the correlation between PD and LGD (including collateral value) on credit risk measures have been considered in the context of corporate loans in recent years. In Frye's (2000a) structural model which draws from the conditional approach suggested by Finger (1999) and Gordy (2000b), collateral and asset values of firms (i.e. borrowers) are modelled using a single index based on a systematic (the state of the economy) and an idiosyncratic risk factor. Correlations between PD and LGD result from joint dependence of borrowers' asset value and of collateral value on the systematic risk factor (i.e. the economic cycle). Frye's (2000b) empirical analysis shows a strong positive correlation between default rates and LGD for corporate bonds. The results allow him to conclude that the economic cycle can produce a double misfortune involving greater-than-average default rate and poor-than-average recoveries.

By incorporating collateral value uncertainty to LGD, Jokivuolle and Peura (2003) propose a model of risky debt in which collateral value is correlated with the PD of a borrower. The borrower's PD is based on the default mechanism proposed by Merton (1974) where the borrower default its debt if its asset value is less than its outstanding liability at the maturity of the debt. Their numerical studies demonstrate the importance of factors such as collateral value volatility and correlation between collateral value and the borrower's asset value for the estimation of credit risk quantity. On a portfolio basis, Altman et al. (2002) use a US corporate bond database covering the period 1982-2000 and find strong evidence of a positive relationship between PD and LGD. They explore through simulation analysis what effect incorporating the positive correlation between PD and LGD has on the value-at-risk for a broadly representative commercial loan portfolio. For their particular simulations they find that setting the correlation between the PD and LGD to zero (as is usual practice), rather than to its estimated value, leads to a reduction in the value-at-risk of at least one quarter. 
Although several models and studies exist to examine the effects of the relationship between PD and LGD on credit losses of corporate loans, the body of research on retail credit risk measurement is quite sparse according to the studies conducted by Allen, DeLong, \& Saunders (2004). In view of this observation, Allen et al. suggest that techniques of credit risk measurement (such as KMV's Portfolio Manager ${ }^{3}$ and Credit Suisse Financial Products' Credit Risk Plus ${ }^{4}$ ) for corporate loans could be applied to retail loans. As PD is also assumed to be independent from LGD in these two techniques, the corresponding expected losses remain simply measured as PD times LGD.

Apart from correlation between PD and LGD, the time horizon of the expected-loss measure, which is defined in Basel II as 1 year, also raises a concern with underestimating provisioning requirements. In order to ensuring adequate level of provisions being provided by banks for expected losses, it is necessary for banks to measure expected losses of retail loans for different time horizons, particularly for long-term secured lending such as residential mortgage loans.

While losses on any single retail loan will not cause a bank to become insolvent, Gross and Souleles (2002) find that retail borrowers were increasingly willing to default on their debt, in large part because of the falling social and legal costs of default. This implies that the provisioning requirements of expected losses for individual banks which are active in retail lending could increase due to higher default rates of the banks' retail loans. The Basel Committee (2001) realises that the longer-term viability of the IRB framework would be enhanced by further international agreement on standards for provisioning of expected loss, as capital adequacy critically depends on accurate valuation of banks' assets and liabilities. This would make it easier to revisit the IRB framework should future efforts to consider changes in the definition of regulatory capital and/or more harmonised provisioning rules be undertaken. In view of the above developments, the measurement of provisions against expected losses of retail lending secured by collateral would be important for improving the capital adequacy framework for banks.

The purpose of this paper is to develop a model for measuring provisions of a pool of collateralised retail loans which have the same collateral type (e.g. residential properties) and broadly the same loan-to-value ratio. The model follows the contingent-claim approach of pricing options developed by Black and Scholes (1973) and Merton (1973). Merton (1974) has also been the pioneer in the pricing of corporate bonds using the contingent-claim framework. He treats default risk equivalent to a European put option on a firm's asset value and the firm's liability is the option strike. To extend the Merton model, structural models with more complex and dynamic liability structures have been considered by Black and Cox (1976), Longstaff and Schwartz (1995), Briys and de Varenne (1997), Collin-Dufresene and Goldstein (2001) and Hui, Lo, and Tsang (2003). These models could explain empirical term structures of credit spreads of corporate bonds with different credit ratings to some extent. Regarding the proposed model in this paper, the pool of collateralised retail loans is equivalent to a put option written by a bank to its borrowers, where the borrowers could walk away by letting the bank reprocess the collateral upon default. The

\footnotetext{
${ }^{3}$ A comparative analysis of these techniques can be found in Crouhy et al. (2000) and Gordy (2000a). KMV's Portfolio Manager is based on the work of Black and Scholes (1973) and Merton (1974) in the pricing of corporate bonds using a contingent-claim framework. In Black-Scholes-Merton's structural framework, a firm's market value of total assets is observable in principle. Furthermore default happens if the total asset value is lower than the value of liabilities. Default risk is therefore equivalent to a European put option on the firm's asset value.

${ }^{4}$ Credit Risk Plus is on the other hand based on the theoretical underpinnings of reduced-form models in which default time is a stopping time of some given hazard rate process and the payoff upon default is specified exogenously. These models have been considered by Jarrow and Turnbull (1995), Jarrow et al. (1997), and Duffie and Singleton (1997).
} 
strike of the put option is the outstanding amount of the loans. When the borrowers default their loans, the loss incurred in the bank is the amount of the loans less the value recovered from the sales of the collateral securing the loans. The loss is the same as a standard payoff of a put option. The provision is therefore equivalent to the option premium multiplied by the PD of borrowers in the pool. The model thus takes account of the stochasticity of the collateral value. The PD of borrowers in the pool over a given time horizon is another stochastic variable in the model. This means that there is a probability that each loan in the pool will default within a time period. The effects of the correlation between PD and the collateral value on the provisioning measures are considered in the model.

It is recognised that the collateral value in a pool of loans will affect its associated PD, in particular when the loans are in negative equity. In general, the collateral value (such as property value) is closely correlated with movements in personal income over time. Also, changes in local unemployment rates are strongly correlated with changes in personal income growth. Both are good measures of the state of the local economy. Therefore, changes in local unemployment rates can be expected to do a good job of explaining changes in default rates. They could also reflect changes in the prevalence of a trigger event such that some borrowers will have reason to examine their financial situations. Empirically, Campbell and Dietrich (1983) find that during the 1960s and 1970s default for insured residential mortgages has been significantly influenced by changes in regional rates of unemployment in the US. Similarly, Agarwal and Liu (2003) find that unemployment is a significant determinant of a household's delinquency and bankruptcy decision by focusing on the credit card market in the US. As changes in unemployment rates reflect the states of an economic cycle, these empirical findings support that the PD of residential mortgage loans could be affected by an economic cycle. The dynamics of the PD of retail loans could thus be assumed to follow a mean-reverting random process, which is more general than a pure-random process and captures the characteristics of an economic cycle. ${ }^{5}$ The PD and the parameters governing its dynamics can be obtained from a bank's historical default data of their retail portfolios.

We derive a closed-form formula from the model as a function of the collateral value and PD to measure the provision of a pool of collateralised retail loans. The two stochastic variables are explicitly correlated in the model. The model allows the PD to follow a mean-reverting process. The model parameters such as, the volatility, correlation and drift of PD are time dependent in the derivation. The model structure, that fits well with the data typically available for banks, can be applied to measuring provisions of retail lending secured by collateral. More accurate measurement of provisioning requirements would enhance banks' capabilities of managing credit risk of such lending.

The scheme of this paper is as follows. In the following section, we develop the model of measuring provisions based on the proposed dynamics of the PD and collateral value. The corresponding closed-form formula is derived. In Section 3, we present some empirical findings of the dynamics of the PD of residential mortgage loans and property values based on the residential mortgage market in Hong Kong. The impact of the model parameters on required provisions is studied in Section 4. In the last section we shall summarise our investigation.

\footnotetext{
5 The mean-reverting process has also been adopted for modelling the dynamics of risk-free interest rates with cyclical characteristics. Interest rates appear to be pulled back to some long-run mean level over time (see Vasicek, 1977) according to different states of an economy cycle. When interest rates are high, the economy tends to slow down and there is less requirement for funds on the part of borrowers. As a result, rates decline. When rates are low, there tends to be a high demand for funds on the part of borrowers. As a result, rates tend to rise.
} 


\section{Model for measuring provisions}

In the model for measuring provisions of a pool of retail loans, the provision is equivalent to the option premium capturing the expected loss of the loans in negative equity multiplied by the PD of borrowers in the pool. The collateral value is therefore one of the two variables. It is reasonable to assume that the loans in the pool will default subject to the following conditions: (1) trigger events happen drawing borrowers' attention to the financial options to default their obligations in the pool and (2) the collateral value falls substantially below outstanding loan balance. Such conditions give a PD that each loan in the pool would default within a time period. The PD is thus the second variable in the model.

The PD is defined as an average PD of borrowers in a pool of retail loans over a time horizon of $t$. The pool is composed of loans with the same collateral type and broadly the same loan-to-value ratio. Its continuous stochastic movement, which is denoted by $D$, is governed by a mean-reverting lognormal diffusion process. It follows the stochastic differential equation:

$$
\frac{\mathrm{d} D}{D}=\kappa_{D}(t)\left[\ln \theta_{D}(t)-\ln D\right] \mathrm{d} t+\sigma_{D}(t) \mathrm{d} z_{D}
$$

The parameter $\kappa_{D}(t)$ determines the speed of adjustment toward a mean PD of $\theta_{D}(t) . \sigma_{D}(t)$ is the volatility of $D$ and $\mathrm{d} z_{D}$ is a standard Wiener process. The model parameters are time dependent. Eq. (1) implies that $D$ drifts toward $\theta_{D}(t)$ when the level of $D$ is different from the mean PD. When $\kappa_{D}(t)$ is set equal to zero, the dynamics of $D$ is a lognormal diffusion process without any drift.

Let $V$ denote the collateral value securing the loans in the pool. $V$ is assumed to follow a lognormal diffusion process and governed by

$$
\frac{\mathrm{d} V}{V}=\mu_{V}(t) \mathrm{d} t+\sigma_{V}(t) \mathrm{d} z_{V}
$$

where $\sigma_{V}(t)$ and $\mu_{V}(t)$ are the volatility and the rate of return respectively of $V$. This process is considered to be valid for financial collateral such as equities and physical collateral such as real estate collateral (see for example, Kau, Keenan, Muller, \& Epperson, 1992). The differentials of the Wiener processes $\mathrm{d} z_{D}$ and $\mathrm{d} z_{V}$ in the above equations are correlated with

$$
\mathrm{d} z_{D} \mathrm{~d} z_{V}=\rho(t) \mathrm{d} t
$$

By applying Ito's lemma for Eqs. (1)-(3), the partial differential equation governing the value $P(D, V, t)$ of the provision of the pool of retail loans is

$$
\begin{aligned}
\frac{\partial P}{\partial t}= & \frac{1}{2} \sigma_{D}^{2}(t) D^{2} \frac{\partial^{2} P}{\partial D^{2}}+\frac{1}{2} \sigma_{V}^{2}(t) V^{2} \frac{\partial^{2} P}{\partial V^{2}}+\rho(t) \sigma_{D}(t) \sigma_{V}(t) D V \frac{\partial^{2} P}{\partial D \partial V} \\
& +\left[\kappa_{D}(t)\left(\ln \theta_{D}(t)-\ln D\right)\right] D \frac{\partial P}{\partial D}+(r-s) V \frac{\partial P}{\partial V}-r P
\end{aligned}
$$

where $r$ is the risk-free interest rate and $s$ is the dividend if the collateral is equities. It is noted that physical collateral (e.g. residential real estate) could be analogous to a stock providing a known dividend yield. The owner of the collateral may receive a yield (e.g. a rental yield) equivalent to a "dividend yield".

The solution of Eq. (4) is subject to the final condition that represents the loss incurred in a bank over a time horizon of $t$. The amount of the loss depends on the outstanding loan value $L$ of the loans in the pool and the collateral value after time $t$. The value $L$ is the bank's actual exposure after taking repayments for the loan principals over time $t$ into account. 
As the loans in the pool have broadly the same loan-to-value ratio, the pool can be viewed as an aggregated loan. The final condition of the provision is thus specified as

$$
P(D, V, t=0)=D \max (L-V, 0)
$$

where $\max (L-V, 0)$ is the standard payoff of a put option. ${ }^{6}$ The solution of Eq. (4) subject to the final condition (5) is

$$
\begin{aligned}
P(D, V, t)= & D^{\eta(t)} \exp \left[\int_{0}^{t} \alpha\left(t^{\prime}\right) \mathrm{d} t^{\prime}-r t\right] \times\left[L N\left(-\frac{z_{0}}{\sqrt{2 c_{1}}}\right)\right. \\
& \left.-V \exp \left[\int_{0}^{t} \rho\left(t^{\prime}\right) \sigma_{D}\left(t^{\prime}\right) \sigma_{V}\left(t^{\prime}\right) \eta\left(t^{\prime}\right) \mathrm{d} t^{\prime}-(s-r) t\right] N\left(-\frac{z_{0}+2 c_{1}}{\sqrt{2 c_{1}}}\right)\right]
\end{aligned}
$$

where

$$
\begin{aligned}
& \alpha(t)=\left[\kappa_{D}(t) \ln \theta_{D}(t)-\frac{\sigma_{D}^{2}(t)}{2}\right] \eta(t)+\frac{1}{2} \sigma_{D}^{2}(t) \eta^{2}(t) \\
& \eta(t)=\exp \left(-\int_{0}^{t} \kappa_{D}\left(t^{\prime}\right) \mathrm{d} t^{\prime}\right) \\
& z_{0}(V, t)=\ln \left(\frac{V}{L}\right)+(r-s) t-c_{1}(t)+\int_{0}^{t} \mathrm{~d} t^{\prime} \rho\left(t^{\prime}\right) \sigma_{D}\left(t^{\prime}\right) \sigma_{V}\left(t^{\prime}\right) \eta\left(t^{\prime}\right) \\
& c_{1}(t)=\int_{0}^{t} \mathrm{~d} t^{\prime} \frac{\sigma_{V}^{2}\left(t^{\prime}\right)}{2}
\end{aligned}
$$

and $N$ is the cumulative normal distribution function.

The detailed derivation of the solution in Eq. (6) is given in Appendix A. When the model parameters are constant or time-dependent functions which can be integrated, $z_{0}(t)$ and $c_{1}(t)$ can be integrated analytically and Eq. (6) is thus in a closed form.

The closed-form solution in Eq. (6) involves nothing more complex than the standard normal distribution function in terms of $D$ and $V$. It has an intuitive structure. It is composed of a putoption solution as a function of $V$ multiplied by a factor as a function of $D$. The put-option part is a decreasing function of the collateral value $V$ and depends on $V$ and $L$ only through their loan-to-value ratio $(L / V)$. The ratio therefore provides a summary measure of facility risk (i.e. LGD) and can be used by banks for categorising internal facility ratings of retail loans. Similarly to a put option, the provision is an increasing function of $\sigma_{V}(t)$.

The value of $D$ affects the provision of the pool as a multiplication factor with a scale factor of $\eta(t)$ in the solution. The dynamics of $D$ affects the provision indirectly through its correlation $\rho$ with $V$. A large and negative $\rho$ reduces the value of the second minus term of the solution through $\exp \left[\int_{0}^{t} \mathrm{~d} t^{\prime} \rho\left(t^{\prime}\right) \sigma_{D}\left(t^{\prime}\right) \sigma_{V}\left(t^{\prime}\right) \eta\left(t^{\prime}\right)\right]$ and thus increases $P(D, V, t)$. This is consistent with the intuition regarding some retail lending such as residential mortgage loans where the decrease in property prices will increase the default rate of the loans (i.e. $\rho<0$ ), that increases the required provision. Eq. (6) also shows that the provision is an increasing function of $\theta_{D}(t)$. This means that

\footnotetext{
${ }^{6}$ Regarding residential mortgage loans with a mortgage-insurance scheme, if an insurance coverage of $I$ due to default is in place, the final condition is modified as $\max (L-V-I, 0)$.
} 


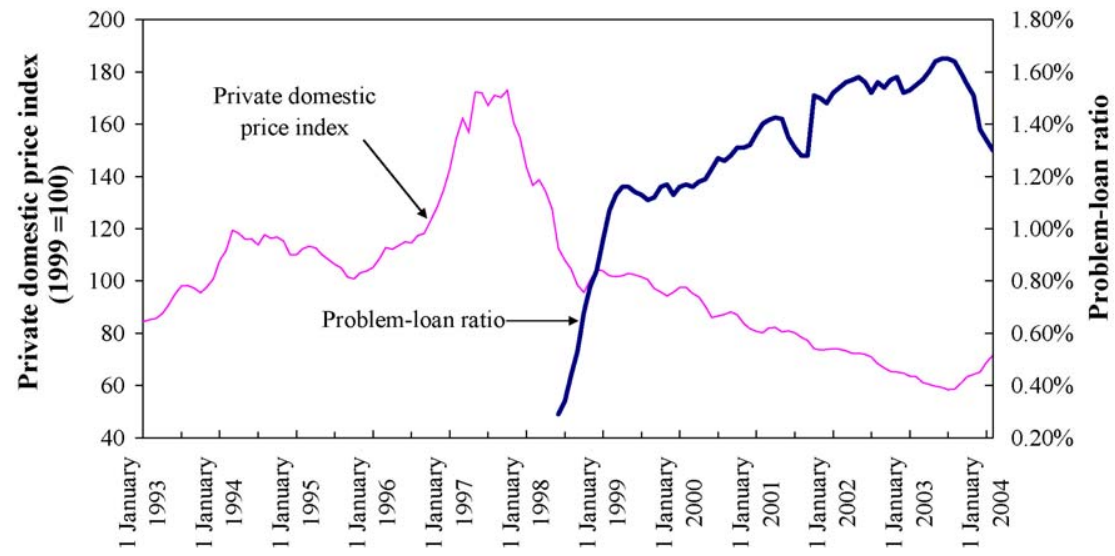

Fig. 1. Private domestic price index $(V)$ and problem-loan ratio $(D)$ of residential mortgage loans.

an increase in the mean level of $D$ implies a higher provision of a retail loan portfolio. When the current $D$ is lower (higher) than $\theta_{D}(t), \kappa_{D}(t)$ drifts $D$ higher (lower) toward $\theta_{D}(t)$. A corresponding increase in $\kappa_{D}(t)$ will increase (decrease) the provision. If $\kappa_{D}(t)$ is sufficiently large, $D$ would stick to $\theta_{D}(t)$ with very small random movement and becomes stationary.

\section{Empirical analysis}

In this section, we present some empirical findings of the dynamics of the PD of residential mortgage loans and property values based on the data of the residential mortgage market in Hong Kong. The data sample is the monthly private domestic price index in Hong Kong, and the monthly problem-loan ratio which is defined as the sum of the delinquency ratio (i.e. overdue more than three months) and the rescheduled-loan ratio of residential mortgage loans in banks. The problemloan ratio can be viewed as a proxy of the default rate of the loans. It is however noted that a 1-year default rate is expected to be higher than the problem-loans ratio as the default rate is a cumulative figure while the number of problem loans will be reduced after writing off the loans. The data consists of residential mortgage loans with different loan-to-value ratios. The sample does not differentiate between loans in positive value and in negative value. The problem-loan ratio and the private domestic price index represent the dynamical variables of the $\mathrm{PD}(D)$ and the collateral value ( $V$ ) specified in Eqs. (1) and (2), respectively. The sample, which covers the periods from June 1998 to February 2004 for $D$ and from January 1993 to February 2004 for $V$, are published by the Hong Kong Monetary Authority and the Rating and Valuation Department of the Hong Kong SAR Government respectively. ${ }^{7}$ This provides with 69 observations for $D$ and 134 observations for $V$. The data series and their descriptive statistics are presented in Fig. 1 and Table 1, respectively. Using the augmented Dickey-Fuller (ADF) test and the maximum-likelihood technique on the available monthly data, the problem-loan ratio of residential mortgage loans is shown to follow a mean-revering process. We also describe the econometric approach used for estimating the model parameters relating to $D$ and $V$.

\footnotetext{
7 The data can be obtained at http://www.info.gov.hk/hkma/eng/statistics/msb/attach/T0307.xls and http://www. rvd.gov.hk/en/publications/pro-review.htm.
} 
Table 1

Statistics of the data series of $V$ and $D$

\begin{tabular}{|c|c|c|c|c|c|c|}
\hline Variables & Number of samples & Data coverage & Sample mean & Standard derivation & Minimum & Maximum \\
\hline$V$, private domestic price index $(1999=100)$ & 134 & January 1993 to February 2004 & 100.6 & 27.8 & 58.4 & 172.9 \\
\hline Monthly price change ${ }^{a}$ & 133 & February 1993-2004 & -0.0012 & 0.0314 & -0.1259 & 0.0930 \\
\hline$D$, problem-loan ratio & 69 & June 1998 to February 2004 & 0.0129 & 0.0031 & 0.0029 & 0.0165 \\
\hline
\end{tabular}

a The monthly price change is defined as $\ln (\operatorname{PPI}(t))-\ln (\operatorname{PPI}(t-1))$, where PPI is the private domestic price index. 
Applying Ito's Lemma and defining $X=\ln D$ and $Y=\ln V$, Eqs. (1) and (2) are respectively rewritten as

$$
\begin{aligned}
& \mathrm{d} X=\kappa_{D}(t)\left[\ln \theta_{D}(t)-\frac{1}{2} \sigma_{D}^{2}(t)-X\right] \mathrm{d} t+\sigma_{D}(t) \mathrm{d} z_{D} \\
& \mathrm{~d} Y=\left[\mu_{V}(t)-\frac{1}{2} \sigma_{V}^{2}(t)\right] \mathrm{d} t+\sigma_{V}(t) \mathrm{d} z_{V}
\end{aligned}
$$

The log values can be characterised by an Ornstein-Uhlenbeck process. Following Brennan and Schwartz (1982), Marsh and Rosenfeld (1983) and Dietrich-Campbell and Schwartz (1986), we can estimate the parameters of the continuous-time model in Eqs. (11) and (12) using the following discrete-time econometric specification:

$$
\begin{aligned}
& Z_{t+1}-Z_{t}=\alpha_{Z}+\beta_{Z} Z_{t}+\varepsilon_{Z, t+1} \\
& E\left[\varepsilon_{Z, t+1}\right]=0, \quad E\left[\varepsilon_{Z, t+1}^{2}\right]=\sigma_{Z}^{2}
\end{aligned}
$$

where $Z$ refers to $X$ or $Y$. It is worthy mentioning that the econometric specification in Eqs. (13) and (14) assumes that the model parameters are independent of time. This specification is therefore regarded as a time-independent case of the model described in Section 2. The corresponding model parameters in Eqs. (1) and (2) can be found by

$$
\begin{aligned}
& \kappa_{D}=-\beta_{X} \\
& \sigma_{D}=\sqrt{\sigma_{X}^{2}} \\
& \theta_{D}=\exp \left(\frac{2 \alpha_{X}-\beta_{X} \sigma_{X}^{2}}{-2 \beta_{X}}\right) \\
& \mu_{V}=\alpha_{Y}+\frac{1}{2} \sigma_{Y}^{2} \\
& \sigma_{V}=\sqrt{\sigma_{Y}^{2}}
\end{aligned}
$$

Our econometric approach is to estimate Eqs. (13) and (14) for $X$ (i.e. $\ln D$ ) and $Y$ (i.e. $\ln V$ ) using the maximum-likelihood method. The maximum-likelihood technique has been used in empirical tests of continuous-time models of interest rates by Marsh and Rosenfeld (1983), De Munnik and Schotman (1994) and Bail (1999). In regard of $X$ and $Y$ respectively, we begin by estimating models specified in Eqs. (13) and (14), and assuming $\beta_{Y}=0$. These specifications assume that the dynamics of $X$ and $Y$ follow the model description in Section 2. Further to this estimation, we consider other model specifications. For $X$, we consider another specification by restricting the parameters in Eq. (13) to $\alpha_{X}=\beta_{X}=0$, i.e. no mean-reverting process for $X$. For $Y$, we consider a restriction of $\alpha_{Y}=0$ in Eq. (13), i.e. $\mu_{Y}=\sigma_{Y}^{2} / 2$. The appropriateness of the model restrictions for $X$ and $Y$ is evaluated using the likelihood ratio test.

Table 2 presents the parameter estimates, asymptotic $t$-statistics, coefficient of determination $\left(R^{2}\right)$ and log-likelihood statistics (LL) for the unrestricted model and the restricted models of $X$ and $Y$. The likelihood ratio (LR) test statistics of the restricted models are computed to evaluate the appropriateness of the model restriction. For $X$, the LR test statistic is 81.0620 and the null hypothesis of the test is $\alpha_{X}=\beta_{X}=0$. As the test involves two restrictions on the parameters, the test statistic has a chi-squared distribution with two degrees of freedom $\left(\chi_{2}^{2}\right)$. As the probability of the $\chi_{2}^{2}$ variable being larger than 5.9918 is $5 \%$ and the LR test statistic is $81.0620(>5.9918)$, the null 
Table 2

Maximum likelihood estimates of alternative models of $X(\ln D)$ and $Y(\ln V)$

\begin{tabular}{|c|c|c|c|c|c|c|c|c|c|c|}
\hline Model (restriction) & $\alpha_{X}$ & $\beta_{X}$ & & $\sigma_{X}$ & & $R^{2}$ & LL & LR ( $p$-value) & $\chi_{(0.05)}^{2}$ & d.f. \\
\hline Unrestricted model of $X$ & $-0.6368(-11.0417)$ & -0 . & $(-11.4593)$ & 0.0 & $1.6261)$ & 0.6595 & 190.315 & - & - & - \\
\hline Restricted model of $X\left(\alpha_{X}=\beta_{X}=0\right)$ & - & - & & 0.0 & $1.7126)$ & -0.1215 & 149.784 & $81.0620(0.0000)$ & 5.9918 & 2 \\
\hline Model (restriction) & $\alpha_{Y}$ & $\beta_{Y}$ & $\sigma_{Y}$ & & $R^{2}$ & $\mathrm{LL}$ & \multicolumn{2}{|c|}{ LR ( $p$-value) } & $\chi_{(0.05)}^{2}$ & d.f \\
\hline Unrestricted & $-0.0012(-0.4560)$ & - & 0.0313 & & 0.0000 & 394 & \multicolumn{2}{|l|}{-} & - & - \\
\hline Restricted model of $Y\left(\alpha_{Y}=0\right)$ & - & - & $0.0314(16$ & 946) & -0.0016 & 394. & \multicolumn{2}{|c|}{$0.2060(0.6499)$} & 3.8415 & 1 \\
\hline
\end{tabular}

The parameter estimates with asymptotic $t$-statistics in parentheses are presented for each model. The maximised log-likelihood statistics (LL) for the unrestricted models and for each of the restricted models are shown to compare the explanatory power of the unrestricted models and restricted models. Likelihood ratio (LR) tests evaluate the restrictions imposed by the restricted models against the unrestricted model. The LR test statistics with the associated $p$-value, degrees of freedom (d.f.) and chi-squared critical values $\left(\chi_{(0.05)}^{2}\right)$ at the $5 \%$ level of significance are reported. The parameters are estimated from the following discrete time system of equations:

$$
Z_{t+1}-Z_{t}=\alpha_{Z}+\beta_{Z} Z_{t}+\varepsilon_{Z, t+1}, \quad E\left[\varepsilon_{Z, t+1}\right]=0, \quad E\left[\varepsilon_{Z, t+1}^{2}\right]=\sigma_{Z}^{2}
$$

where $Z$ refers to $X$ or $Y$. 
hypothesis of $\alpha_{X}=\beta_{X}=0$ is rejected at the $5 \%$ level of significance. The test result suggests that the unrestricted model for $X$ is preferred and $X$ follows a mean-reverting process. The parameter $\beta_{X}$ is negative and implies that $\kappa_{D}$ is positive. This finding is consistent with the model description of the PD in Section 2.

Further investigation is conducted to determine whether the dynamical process of $X$ is meanreverting. A unit root test provides a simple method of testing for mean reversion. The unit root test adopted here is the ADF test of Said and Dickey (1984). Applying the test for $X$, it requires estimating the following ordinary least squares (OLS) regression equation:

$$
X_{t+1}-X_{t}=\alpha_{X}+\beta_{X} X_{t}+\sum_{i=1}^{N} \varphi_{i}\left(X_{t+1-i}-X_{t-i}\right)+\varepsilon_{X, t+1}
$$

The ADF test consists of testing the negativity of $\beta_{X}$ in Eq. (20). To accommodate any serial correlation in the residuals, Eq. (20) is augmented with $N$ lagged difference terms. The null hypothesis of the ADF test is $\beta_{X}=0\left(\kappa_{D}=0\right)$, i.e. $X$ contains a unit root. Rejection of the null hypothesis in favour of the alternative: $\beta_{X}<0\left(\kappa_{D}>0\right)$ implies that $X$ is stationary. Stationarity of $X$ implies that the mean and the variance of $X$ are both constant over time.

In order to test the null hypothesis of the ADF test, it is necessary to know the distribution of the statistic used for the test. In this case, it is the distribution of the Dickey-Fuller statistic of $\beta_{X}$, which is derived by the ratio of the OLS estimate of $\beta_{X}$ to its OLS standard error. Under the null hypothesis where $X$ contains a unit root, the Dickey-Fuller statistic of $\beta_{X}$ does not however have a limiting normal distribution. Dickey and Fuller (1981) show that the distributions of Dickey-Fuller statistics are complicated and, in general, do not have any known analytical forms. It is therefore difficult to find exact critical values for the tests. In practice, critical values are usually approximated through simulation. For example, Cheung and Lai (1995) compute critical values for any sample size and for any number of lagged difference terms using simulation and response surface analysis. The test adopted here is augmented with a drift term $\left(\alpha_{X}\right)$ to use -3.5201 which is given by Cheung and Lai (1995) as the critical values at the $99 \%$ confidence level. The ADF test statistic for $X$ is -6.0470 with one lagged difference term. ${ }^{8}$ The result rejects the null of $\beta_{X}=0$ (i.e. $\kappa_{D}=0$ ) at the $1 \%$ level of significance and thus suggests that $X$ follows a mean-reverting process.

The relative performance of the unrestricted model and the restricted model (i.e. $\alpha_{Y}=0$ ) of $Y$ is evaluated by the LR test statistic. As shown in Table 2, the LR test statistic is 0.2060 . The null hypothesis under consideration is $\alpha_{Y}=0$. The test here involves a single restriction, and thus the test statistic has a chi-squared distribution with one degree of freedom $\left(\chi_{1}^{2}\right)$. As the probability of the $\chi_{1}^{2}$ variable being larger than 3.8415 is 0.05 and the test statistic is $0.2060(<3.8415)$, we accept the null hypothesis of $\alpha_{Y}=0$ at the $5 \%$ level of significance. The result indicates that the restricted model is preferred and $Y$ follows a normal process with no mean reversion. ${ }^{9}$

The model parameters relating to $D$ and $V$ can be obtained from the estimates presented in Table 2. Based on the estimation result of the unrestricted model of $X$ and substituting $\beta_{X}$ of -0.1499 into Eq. (15), the parameter $\kappa_{D}$ in Eq. (1) is estimated to be 0.1499 . Since the estimation of $X$ is based on the monthly time series, the annualised $\kappa_{D}$ is $0.1499 \times 12=1.7988$. The long-run

\footnotetext{
8 The lag length is chosen using the Akaike Information Criteria and the maximum number of lags is set to be 10 .

9 An ADF test shows that $Y$ does not follow a mean-reverting process. The ADF statistic is -2.1110 with a draft and 7 lagged difference terms. Since the critical value at the $90 \%$ confidence interval is -2.5471 and the ADF test statistic is larger than the critical value, the null hypothesis cannot be rejected at the $10 \%$ level of significance.
} 
value $\theta_{D}$ of $D$ can be calculated by substituting the estimates of $\alpha_{X}, \beta_{X}$ and $\sigma_{X}$ from the unrestricted model of $X$ into Eq. (17). The value of $\theta_{D}$ is found to be $0.0144 .{ }^{10}$ It is however noted that the long-run PD of residential mortgage loans in negative equity (i.e. loans with loan-to-value ratios $>1$ ) would be much higher than the estimated value of 0.0144 . The volatility $\sigma_{D}$ of $D$ is obtained by substituting the estimate of $\sigma_{X}$ into Eq. (16) and $\sigma_{D}$ is 0.037 . The annualised volatility of $D$ is $0.037 \times \sqrt{12}=0.1282 .^{11}$

The drift $\mu_{V}$ and volatility $\sigma_{V}$ of $V$ in Eq. (2) can be estimated by substituting the estimate of $\sigma_{Y}$ from the restricted model of $Y$ into Eqs. (18) and (19), respectively. The values of $\mu_{V}$ and $\sigma_{V}$ are estimated to be 0.0005 and 0.0314 , respectively. The annualised $\mu_{V}$ and $\sigma_{V}$ are found to be $0.0005 \times 12=0.006$ and $0.0314 \times \sqrt{12}=0.1087$, respectively. ${ }^{12}$

The value of $\rho$ in Eq. (3) can be approximated by the sample correlation coefficient between the estimated series of $\varepsilon_{X, t}$ and $\varepsilon_{Y, t}$ in Eq. (13). The value of the estimated $\rho$ is -0.2603 . The $t$-statistic for testing the significance of the estimate is $-2.1901 .^{13} \mathrm{It}$ is noted that the test statistic has a $t$-distribution with 66 degrees of freedom (because of the 69 observations for $D$ ) and the $5 \%$ critical value for a two-tail test is \pm 1.9966 . Since the test statistic of -2.1901 is less than -1.9966 , the null hypothesis of no correlation between $\varepsilon_{X, t}$ and $\varepsilon_{Y, t}$ is rejected at the $5 \%$ level of significance.

\section{Numerical results}

The detailed effects of the model parameters on the model provisions required for pools of retail loans are illustrated in the following numerical examples. The current collateral value $V$ of the pool of loans is 1 . The time horizon is 3 years. The average 3 -year PD of the pool is assumed to be $D=5 \%$ and the mean level $\theta_{D}$ of $D$ is set at $8 \%$. As the delinquency ratio of residential mortgage loans in negative equity in Hong Kong was 2.92\% in September 2002, the use of the mean level of the 3-year PD at $8 \%$ is reasonable. ${ }^{14}$ The interest rate $r$ and "dividend" yield $s$ are $2.5 \%$ and $5 \%$ per annum respectively. Different values of $L$ are used to illustrate the model provisions for different loan-to-value ratios.

In order to eliminate the effect of the dynamics of $D$ on provisions in Fig. 2, that will be studied in Fig. 4 below, $\kappa_{D}$ and $\rho$ are set to be zero. Fig. 2 shows that the increases in provisions depend on the loan-to-value ratio $(L / V)$ and the volatility of the collateral value. For $\sigma_{V}=0.1$, the provisions are material when the loan-to-value ratio is larger than 0.8 . When $\sigma_{V}$ increases to 0.2

\footnotetext{
10 The data of the problem-loans ratio (instead of the actual default rate) are used in the estimation. As the number of problem loans will be reduced after writing off the loans, the long-run 1-year default rate is expected to be higher than the estimated figure here.

${ }^{11}$ Based on the data of the property price index during the period from December 1995 to 1998 , its annualised volatility was up to $16.4 \%$.

12 The low mean rate of $0.6 \%$ of appreciation of $V$ per year is also reflected from the price changes in Table 1 , where the simple mean of changes is even smaller at $-0.01 \%$ per year. These low values are due to the continuous decline in the property price index in Hong Kong since 1997 (see Fig. 1).

13 The $t$-statistic is calculated by $t=\rho \sqrt{(n-2) /\left(1-\rho^{2}\right)}$. This $t$-statistic has a student- $t$ distribution with $(n-2)$ degrees of freedom where $n$ is the number of samples.

14 The delinquency ratios of residential mortgage loans in negative equity in Hong Kong have been collected by the Hong Kong Monetary Authority since September 2002. The figure of $2.92 \%$ can be found at http://www.info.gov.hk/hkma/eng/press/index.htm. The maximum of the data series of D is $1.65 \%$ in July 2003 . A 3 year default rate is expected to be higher than the delinquency ratio as the default rate is a cumulative figure while the number of problem loans will be reduced after writing off the loans.
} 


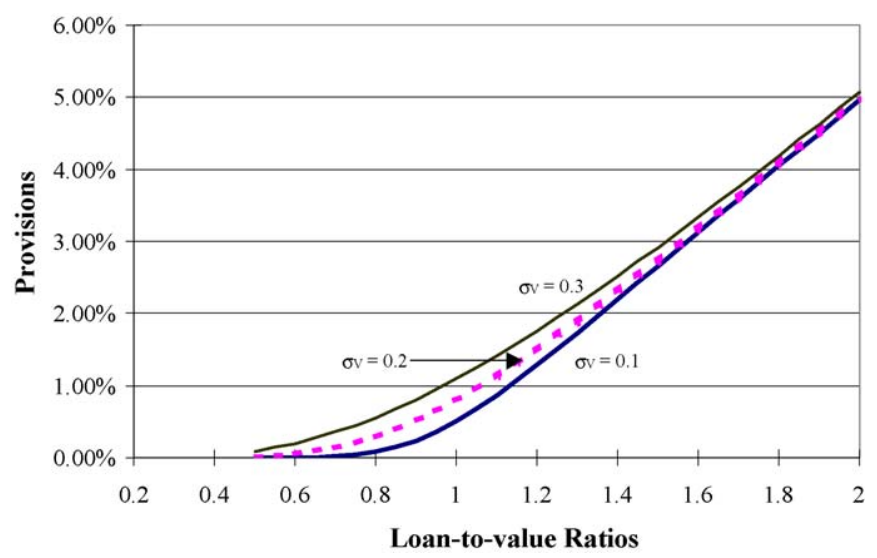

Fig. 2. Provisions of pools of loans with different loan-to-value ratios and volatilities of collateral value for a 3-year time horizon. The volatilities of the collateral value are $\sigma_{V}=0.1,0.2$ and 0.3 . The average 3 -year PD of the pool is $5 \%$ with no mean-reverting movement (i.e. $\kappa_{D}=0$ ) and is uncorrelated with the collateral value (i.e. $\rho=0$ ). Other parameters are $r=2.5 \%, s=5 \%$ and $\sigma_{D}=0.11$.

and 0.3 , the threshold of materiality lowers to about $L / V=0.6$. The results reflect that provisions are still necessary for loans in positive equity (i.e. $L / V<1$ ), in particular where the collateral value is volatile. The increases in provisions with different $\sigma_{V}$ are significant when $L / V$ is around 1 . Because the model adopts the option-pricing approach, this observation is similar to vega risk of a European option (i.e. sensitivity to the change in volatility of the underlying asset of the option), which is at the maximum when the underlying asset value is equal to the strike price. When $L / V$ is larger than 1.6, the impact of the changes in $\sigma_{V}$ is immaterial. ${ }^{15}$ This means that the volatility of collateral value does not affect the provisioning requirements for loans which are deep in negative equity.

The change in the provision with respect to the change in the loan-to-value ratio is studied in Fig. 3, using the same model parameters in Fig. 2. Such change is defined as

$$
\delta=\frac{\Delta P(D, V, t)}{\Delta(L / V)} \frac{1}{D}
$$

which is normalised by $D$ such that $\delta$ is just associated with the loan-to-value ratio. The measure $\delta$ is the elasticity of provisions with respect to the loan-to-value ratio and is similar to the delta risk of a European option (i.e. sensitivity to the change in the value of the underlying asset of the option). The results demonstrate that $\delta$ increases with $L / V$ and is at the maximum of $90 \%$ when $L / V$ is larger than 1.5 . This means that the provisioning requirements for loans in negative equity with $L / V>1.5$ increase almost linearly with a decline in the collateral value. Fig. 3 also shows that $\delta$ increases significantly when the loan-to-value ratios range from 0.8 to 1 . The required provision will change quite rapidly for such a range of the loan-to-value ratios. The result is similar to that in an at-the-money European option of which the delta changes significantly when the underlying asset value is close to the strike price.

Fig. 4 illustrates the impact of the mean-reverting process of $D$ and the correlation $\rho$ between $D$ and $V$ on provisions. The impact is measured as the percentage changes in provisions compared

\footnotetext{
15 Because the property price index in Hong Kong declined 66\% from 173 in 1997 to 58 in 2003 (see Table 1), some residential mortgage loans might have loan-to-value ratios of $160 \%$ or even above.
} 


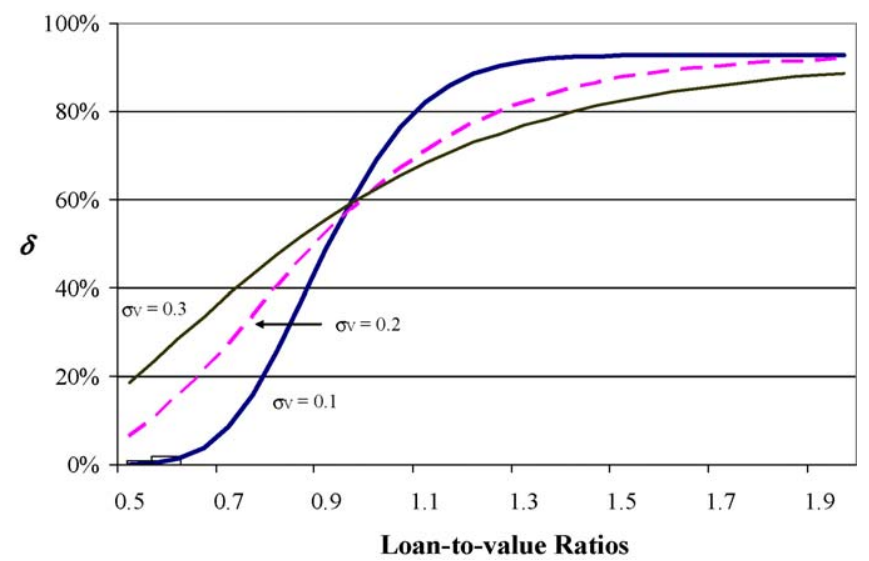

Fig. 3. Changes in provisions with respect to changes in loan-to-value ratios (i.e. $\delta$ ) under different loan-to-value ratios and volatilities of collateral value for a 3 -year time horizon. The volatilities of the collateral value are $\sigma_{V}=0.1,0.2$ and 0.3. The average 3-year PD of the pool is $5 \%$ with no mean-reverting movement (i.e. $\kappa_{D}=0$ ) and is uncorrelated with the collateral value (i.e. $\rho=0$ ). Other parameters are $r=2.5 \%, s=5 \%$ and $\sigma_{D}=0.11$.

with the provisions with zero correlation. Fig. 4 considers three cases: (i) $\kappa_{D}=0$ and $\sigma_{D}=0.22$; (ii) $\kappa_{D}=0$ and $\sigma_{D}=0.11$; (iii) $\kappa_{D}=0.5$ and $\sigma_{D}=0.11$. The volatility $\sigma_{V}$ of $V$ is 0.3 per annum. The provision associated a pool with $\rho=0$ and $\kappa_{D}=0$ is $1.1 \%$. The numerical results show that the percentage changes in provisions increase with the decrease (more negative) in the correlation. The negative $\rho$ implies that the PD increases when the collateral value drops. The amount of loss due to default risk and the corresponding provision thus increases. The changes in provisions may be up to $30 \%$ in the case of negative $\rho, \kappa_{D}=0$ and $\sigma_{D}=0.22$. This means that the effect of correlation between PD and the collateral value is material on measuring provisions. Fig. 4

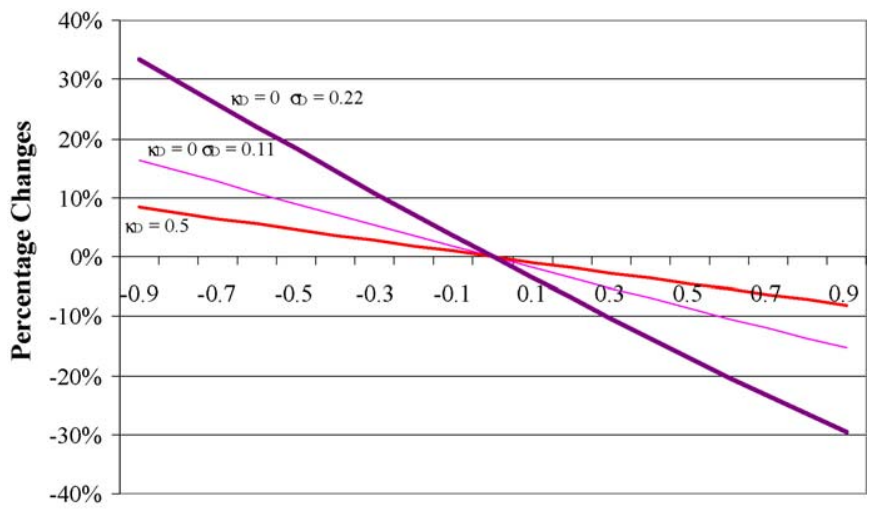

\section{Correlation}

Fig. 4. Percentage changes in provisions of pools of loans with different correlation between collateral value and PD compared with the provisions with zero correlation under different dynamics of PD. The loan-to-value ratio $(L / V)$ is 1 and the time horizon is 3 years. The volatility of the collateral value is $\sigma_{V}=0.3$. The dynamics of PD is defined as: (i) $\kappa_{D}=0$ and $\sigma_{D}=0.22$; (ii) $\kappa_{D}=0$ and $\sigma_{D}=0.11$; (iii) $\kappa_{D}=0.5$ and $\sigma_{D}=0.11$. The average 3 -year PD of the pool is $5 \%$ with the mean level $\theta_{D}$ of $D$ at $8 \%$. Other parameters are $r=2.5 \%$ and $s=5 \%$. The provision associated with $\rho=0$ and $\kappa_{D}=0$ is $1.1 \%$. 


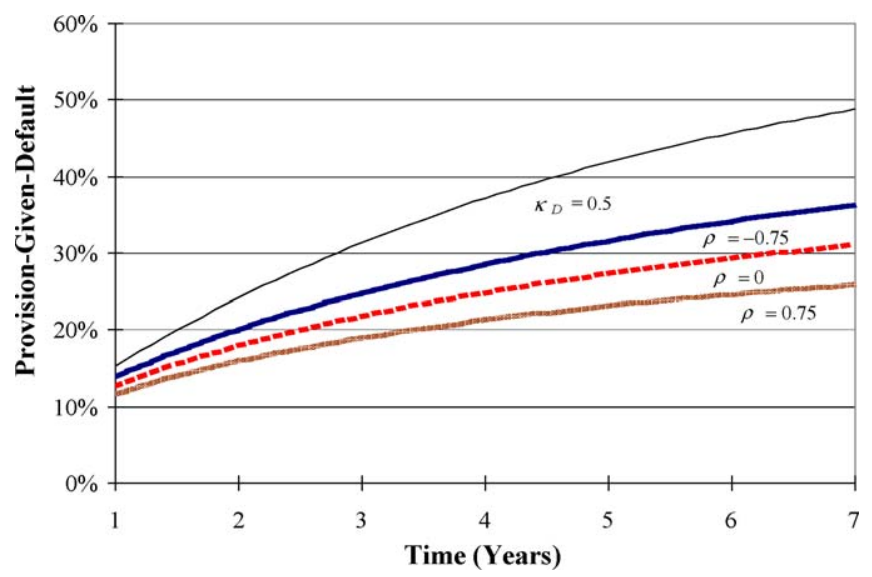

Fig. 5. Provision-given-default of pools of loans with different time horizons and correlation between collateral value and PD. The loan-to-value ratio $(L / V)$ is 1 and the volatility of the collateral value is $\sigma_{V}=0.3$. The four lines represent (i) $\rho=-0.75$ and $\kappa_{D}=0$; (ii) $\rho=0$ and $\kappa_{D}=0$; (iii) $\rho=0.75$ and $\kappa_{D}=0$; (iv) $\rho=0$ and $\kappa_{D}=0.5$. The mean level $\theta_{D}$ of $D$ is at $8 \%$. Other parameters are $r=2.5 \%, s=5 \%$ and $\sigma_{D}=0.11$.

shows that the increase in $\kappa_{D}$ reduces the changes in provisions with $\rho$. The positive $\kappa_{D}$ implies a stationary movement of $D$ and the effect on changes in provisions due to the correlation is reduced. The result is consistent with the property of the function $z_{0}(V, t)$ in the solution of Eq. (6), which shows that the positive $\kappa_{D}$ gives a discounting effect on the covariance term $\rho(t) \sigma_{D}(t) \sigma_{V}(t)$. The numerical results demonstrate that the effect of an economic cycle (i.e. the present of a meanreverting process) on the PD could reduce the impact of the correlation on provisions. Fig. 4 also shows that the increase in $\sigma_{D}$ increases the changes in provisions with $\rho$, by comparing the results of the cases with $\sigma_{D}=0.22$ and 0.11 . This observation illustrates that the volatility of the PD may affect provisions through its correlation with the collateral value.

The required provision-given-default is defined as $P(D, V, t) / D$ and is a measure similar to loss-given-default (LGD). Its properties are illustrated in Fig. 5 based on four cases: (i) $\rho=-0.75$ and $\kappa_{D}=0$; (ii) $\rho=0$ and $\kappa_{D}=0$; (iii) $\rho=0.75$ and $\kappa_{D}=0$; (iv) $\rho=0$ and $\kappa_{D}=0.5$. The volatility $\sigma_{V}$ and $\sigma_{D}$ of $V$ and $D$ are 0.3 and 0.11 per annum, respectively. The loan-to-value ratio equal to 1 is used for the calculations. The results show that the provision-given-default increases with time horizons. This property is consistent with the intuition that the uncertainty of the collateral coverage (i.e. LGD) increases with time. The rate of the increments of the provision-given-default with time in case (i) is higher than those in cases (ii) and (iii) with higher $\rho$. This reflects that the negative correlation between the PD and collateral value increases the uncertainty of the collateral coverage (i.e. LGD) for loans over time. For case (iv) with $\rho=0$ and $\kappa_{D}=0.5$, as the mean-reverting drift of $D$ would pull the current $D=5 \%$ to the mean level of $\theta_{D}=8 \%$ over time, the mean-reverting process causes the highest rate of the increments of the provision-given-default with time in case (iv). The results in Fig. 5 demonstrate that collateralised retail loans (in particular long-term lending) require different amounts of provisions for different time horizons.

\section{Summary}

This paper develops a simple model for measuring the provision for a pool of collateralised retail loans with homogenous characteristics (i.e. the same type of collateral and broadly the same 
loan-to-value ratio), where the collateral coverage is treated as a put option with the strike price equal to the outstanding loan amount of the pool. The collateral value and the PD of borrowers in the pool are the two correlated stochastic variables in the model. A closed-form formula of the model is derived and used to calculate the required provision for a pool of loans over a given time horizon. Empirical findings based on the data of the residential mortgage market in Hong Kong are consistent with the proposed mean-reverting dynamics of the PD of residential mortgage loans. The numerical results show that the loan-to-value ratio, correlation between the collateral value and the PD, volatility of the collateral value, mean-reverting process of the PD and time horizon are the important factors for measuring provisions and what are their effects. As the information associated with these factors is in general available in banks' retail portfolios, the model can be readily incorporated into their internal risk management systems as a useful quantitative tool for measuring provisions.

\section{Acknowledgements}

This work is partially supported by the Direct Grant for Research from the Research Grants Council of the Hong Kong SAR Government. For helpful comments, we are grateful to the referee and Hans Genberg. The conclusions herein do not represent the views of the Hong Kong Monetary Authority.

\section{Appendix A}

Without loss of generality, the solution $P(D, V, t)$ is rewritten in the form:

$$
P(D, V, t)=D^{\eta(t)} F(V, t) \exp \left[\int_{0}^{t} \alpha\left(t^{\prime}\right) \mathrm{d} t^{\prime}\right]
$$

where $\alpha(t)$ and $\eta(t)$ are defined in Eqs. (7) and (8) respectively. $F(V, t)$ satisfies the following partial differential equation:

$$
\frac{\partial F}{\partial t}=\frac{1}{2} \sigma_{V}^{2}(t) V^{2} \frac{\partial^{2} F}{\partial V^{2}}+\left[r-s+\rho(t) \sigma_{D}(t) \sigma_{V}(t)\right] V \frac{\partial F}{\partial V}-r F
$$

and the corresponding final condition is given by

$$
F(V, t=0)=L \max [1-(V / L), 0]
$$

It is then not difficult to show that $F(V, t)$ is given by (Lo and Hui, 2001) as

$$
F(V, t)=\int_{-\infty}^{\infty} \mathrm{d} y K(V, t ; y, 0) F(y, 0)=L \int_{-\infty}^{0} \mathrm{~d} y K(V, t ; y, 0)[1-\exp (y)]
$$

where

$$
K(V, t ; y, 0)=\frac{\exp (-r t)}{\sqrt{4 \pi c_{1}(t)}} \exp \left\{-\frac{\left[y-z_{0}(V, t)\right]^{2}}{4 c_{1}(t)}\right\}
$$


is the kernel of Eq. (A.2), and $z_{0}(V, t)$ and $c_{1}(t)$ are defined in Eqs. (9) and (10), respectively. The integral in Eq. (A.4) can be evaluated analytically to yield a closed-form solution of

$$
F(V, t)=L \exp (-r t) \times\left[N\left(-\frac{z_{0}}{\sqrt{2 c_{1}}}\right)-\exp \left(z_{0}+c_{1}\right) N\left(-\frac{z_{0}+2 c_{1}}{\sqrt{2 c_{1}}}\right)\right]
$$

After substituting Eq. (A.6) into Eq. (A.1), the solution of Eq. (6) is obtained.

\section{References}

Agarwal, S., \& Liu, C. (2003). Determinants of credit card delinquency and bankruptcy: Macroeconomic factors. Journal of Economics and Finance, 27, 75-84.

Allen, L., DeLong, G., \& Saunders, A. (2004). Issues in the credit risk modeling of retail markets. Journal of Banking and Finance, 28, 727-752.

Altman, E., Resti, A., Sironi, A. (2002). The link between default and recovery rates: Effects on the procyclicality of regulatory capital ratios (Working Paper), BIS, Basel.

Bali, T. G. (1999). An empirical comparison of continuous time models of the short term interest rate. Journal of Futures Markets, 19(7), 777-797.

Basel Committee on Banking Supervision (2000). Principles for the Management of Credit Risk, BIS, Basel.

Basel Committee on Banking Supervision (2001). The IRB treatment of expected losses and future margin income (Working Paper), BIS, Basel.

Basel Committee on Banking Supervision (2004). International convergence of capital measurement and capital standards: A revised framework, BIS, Basel.

Black, F., \& Cox, J. (1976). Valuing corporate securities: Some effects of bond indenture provisions. Journal of Finance, $35,1223-1234$.

Black, F., \& Scholes, M. (1973). The pricing of options and corporate liability. Journal of Political Economics, 81, 637-654.

Brennan, M. J., \& Schwartz, E. S. (1982). An equilibrium model of bond pricing and a test of market efficiency. Journal of Financial and Quantitative Analysis, 17, 301-329.

Briys, E., \& de Varenne, F. (1997). Valuing risky fixed rate debt: An extension. Journal of Financial and Quantitative Analysis, 32, 230-248.

Campbell, T. S., \& Dietrich, J. K. (1983). The determinants of default on insured conventional residential mortgage loans. Journal of Finance, 38, 1569-1581.

Cheung, Y. W., \& Lai, K. S. (1995). Lag order and critical values of the augmented Dickey-Fuller test. Journal of Business and Economic Statistics, 13, 277-280.

Collin-Dufresene, P., \& Goldstein, R. S. (2001). Do credit spreads reflect stationary leverage ratio? Journal of Finance, 56, 1929-1957.

Crouhy, M., Galai, D., \& Mark, R. (2000). A comparative analysis of current credit risk models. Journal of Banking and Finance, 24, 57-117.

De Munnik, J., \& Schotman, P. (1994). Cross sectional versus time series estimation of term structure models: Empirical results for the Dutch bond market. Journal of Banking and Finance, 18, 997-1025.

Dickey, D. A., \& Fuller, W. A. (1981). Likelihood ratio statistics for autoregressive time series with a unit root. Econometica, 49, 1057-1072.

Dietrich-Campbell, B., \& Schwartz, E. S. (1986). Valuing debt options: Empirical evidence. Journal of Financial Economics, 16, 321-343.

Duffie, D., \& Singleton, K. J. (1997). An econometric model of the term structure of interest-rate swap yields. Journal of Finance, 52, 1287-1322.

Finger, C. (1999). Conditional approaches for CreditMetrics portfolio distributions, CreditMetrics Monitor, April.

Frye, J. (2000a, October). Collateral damage detected, Federal Reserve Bank of Chicago (Working Paper, Emerging Issues Series, pp. 1-14).

Frye, J. (2000b, November). Depressing recoveries, Risk, 91-4.

Gordy, M. B. (2000a). A comparative anatomy of credit risk models. Journal of Banking and Finance, 24, 119-149.

Gordy, M. B. (2000b, March). Credit VaR models and risk-bucket capital rules: A reconciliation (Working Paper), Federal Reserve Board. 
Gross, D. B., \& Souleles, N. S. (2002). An empirical analysis of personal bankruptcy an delinquency. Review of Financial Studies, 15, 319-347.

Hui, C. H., Lo, C. F., \& Tsang, S. W. (2003). Pricing corporate bonds with dynamic default barriers. Journal of Risk, 5(3), $17-37$.

Jarrow, R., \& Turnbull, S. (1995). Pricing options on financial securities subject to default risk. Journal of Finance, 50, 53-86.

Jarrow, R., Lando, A., \& Turnbull, S. (1997). A Markov model for the term structure of credit spreads. Review of Financial Studies, 10, 481-523.

Jokivuolle, E., \& Peura, S. (2003). Incorporating collateral value uncertainty in loss given default estimates and loan-tovalue ratios. European Financial Management, 9, 299-314.

Kau, J. B., Keenan, D. C., Muller, W. J., \& Epperson, J. F. (1992). A generalised valuation model for fixed-rate residential mortgages. Journal of Money, Credit and Banking, 24, 279-299.

Lo, C. F., \& Hui, C. H. (2001). Valuation of financial derivatives with time-dependent parameters—Lie algebraic approach. Quantitative Finance, 1, 73-78.

Longstaff, F., \& Schwartz, E. (1995). A simple approach to valuing risky fixed and floating rate debt. Journal of Finance, $50,789-819$.

Marsh, T. A., \& Rosenfeld, E. R. (1983). Stochastic processes for interest rates and equilibrium bond prices. Journal of Finance, 38, 635-646.

Merton, R. C. (1973). Theory of rational option pricing. Bell Journal of Economics and Management Science, 4, 141-183.

Merton, R. C. (1974). On the pricing of corporate debt: The risk structure of interest rates. Journal of Finance, 29, 449-470.

Said, S. E., \& Dickey, D. A. (1984). Testing for unit roots in autoregressive moving average models of unknown order. Biometrika, 71, 599-607.

Vasicek, O. A. (1977). An equilibrium characterisation of the term structure. Journal of Financial Economics, 5, 177-188.

World Bank. (2002). In A. Laurin \& G. Majnoni (Eds.), Bank loan classification and provisioning practices in selected developed and emerging countries. 